Review

\title{
Iron Phthalocyanine/Graphene Composites as Promising Electrocatalysts for the Oxygen Reduction Reaction
}

\author{
Jong S. Park ${ }^{1}$ and Dong Wook Chang ${ }^{2, *(1)}$ \\ 1 Department of Organic Material Science and Engineering, Pusan National University, Busan 46241, Korea; \\ jongpark@pusan.ac.kr \\ 2 Department of Industrial Chemistry, Pukyong National University, Busan 48513, Korea \\ * Correspondence: dwchang@pknu.ac.kr; Tel.: +82-51-629-6444
}

Received: 21 May 2020; Accepted: 31 July 2020; Published: 6 August 2020

\begin{abstract}
Recently, the development of non-precious electrocatalysts for the oxygen reduction reaction (ORR) has become important in replacing currently employed platinum (Pt)-based catalysts. Although Pt-based catalysts exhibit satisfactory ORR performances, their high price, easy methanol/ $/ \mathrm{CO}_{2}$ poisoning, and poor long-term stability significantly hamper the forward movement of fuel cell technology. Among the various candidates, graphene-supported iron phthalocyanine $(\mathrm{FePc})$ composites have attracted great attention because of their unique advantages, including low cost, good dimensional stability, high durability, and tunable catalytic activity. In the composite catalyst, FePc molecules are immobilized on graphene via noncovalent or covalent interactions. In addition, two-dimensional graphene substrates can improve not only the electrical conductivity of the composite, but also the dispersion of FePc molecules, triggering a significant improvement in the catalytic properties of the composite catalyst. Herein, we summarize the recent advances in FePc/graphene composite catalysts used for the ORR. Moreover, we discuss the challenges and future perspectives of this promising field.
\end{abstract}

Keywords: electrocatalysts; oxygen reduction reaction; graphene; iron phthalocyanine; composite

\section{Introduction}

As demand to reduce emerging environmental and energy-related global issues has increased, enormous attention has been paid to the development of green and sustainable resources for energy conversion and storage applications. Direct methanol fuel cells (DMFCs), in which the chemical energy of a fuel is directly converted to useful electrical energy through electrochemical reactions (Figure 1A), are of particular importance due to their unique advantages, such as high power density, minimized pollutant emission, long operational time, and good safety [1,2]. One of the major obstacles in DMFC technology is the sluggish kinetics of the oxygen reduction reaction (ORR), which occurs at the cathode. This not only decreases the overall performance of DMFCs, but also requires a high loading of noble platinum $(\mathrm{Pt})$ catalysts [3,4]. The mechanism of ORR usually follows either a two-step two-electron pathway or a one-step four-electron pathway. The former generates undesirable $\mathrm{H}_{2} \mathrm{O}^{-}$ (in an alkaline medium) or $\mathrm{H}_{2} \mathrm{O}_{2}$ (in an acidic medium) intermediate species, while the latter involves the favorable direct reduction of $\mathrm{O}_{2}$ molecules into $\mathrm{OH}$ - (in an alkaline medium) or $\mathrm{H}_{2} \mathrm{O}$ (in an acidic medium) (Figure 1B) [5]. Although Pt-based catalysts exhibit satisfactory catalytic activities toward the ORR, the large-scale production of DMFCs is significantly impeded by the high cost and limited supply of Pt. In addition, these noble Pt catalysts suffer from several serious drawbacks, such as methanol crossover, $\mathrm{CO}_{2}$ poisoning, and low operational stability [6]. To address these problems, 
the development of alternative non-precious metal or metal-free catalysts has become crucial. A number of candidates have been considered so far, including hetero-atom-doped carbon materials [7-10], metal-chalcogenides [11,12], conducting polymers [13,14], transition metal oxides [15,16], and metal chelates $[17,18]$. However, these materials possess significant drawbacks, and are still difficult to be commercialized. For example, the catalytic performances of most hetero-atom-doped carbon materials are inferior to those the conventional Pt-based catalysts, and metal-chalcogenides often require complicated and costly synthetic methods [6]. In the case of conducting polymers, although they can provide the structural tunability and high porosity, the scalable and reproducible synthetic approaches need to be developed [13]. In addition, the practical application of metal oxides and metal chelates is limited, due to the poor electrical conductivity and low stability in acidic media, respectively [19-22].

A

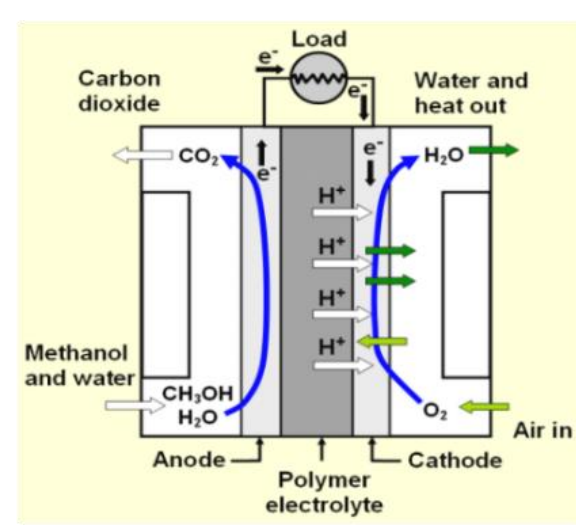

$\mathrm{C}$

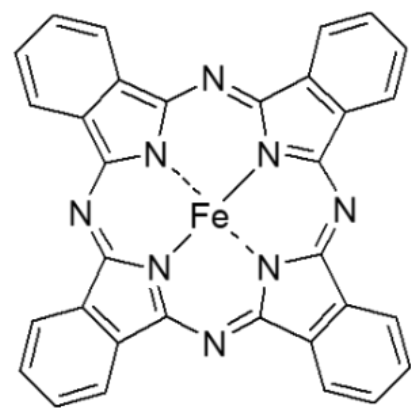

B

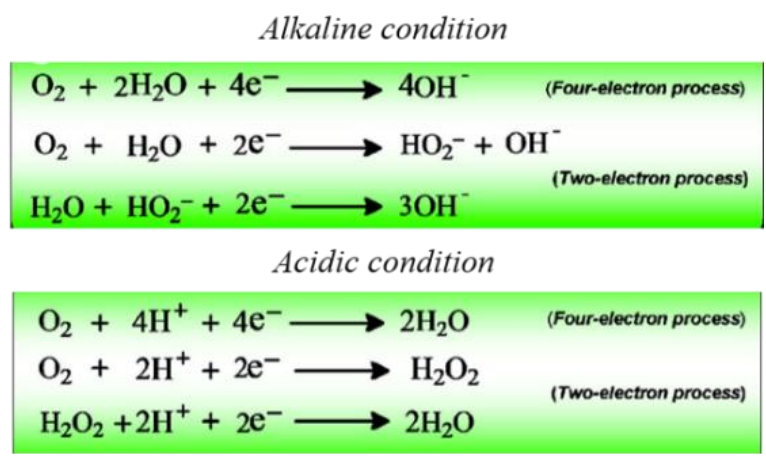

$\mathrm{D}$

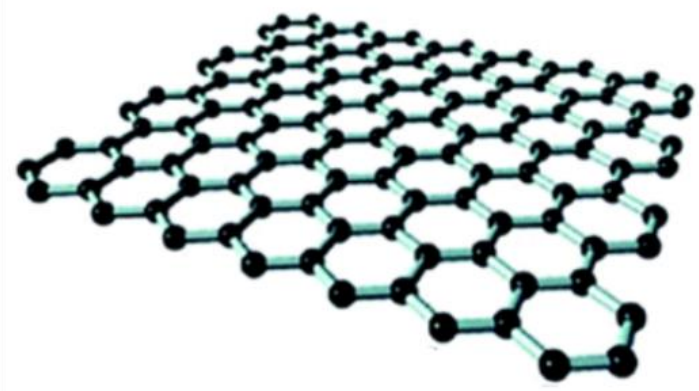

Figure 1. (A) Schematic of direct methanol fuel cells (DMFC), adapted from ref [23], (B) The oxygen reduction reaction in alkaline and acidic conditions, adapted from ref [5] Copyright 2010 American Chemical Society. Chemical structure of (C) iron phthalocyanine (FePc), and (D) two-dimensional graphene, adapted from ref [24] Copyright 2016 Elsevier.

Among several candidates, metallo-phthalocyanine (MPc) has attracted great attention owing to its low cost, good dimensional stability, and tunable catalytic activity [25-27]. MPc generally exhibits peculiar spectral, optical, and electrochemical characteristics, aside from excellent chemical and thermal stability. Depending on the inserted metal ions and the peripheral substituents, the resulting MPc properties can be effectively modified, which finds it suitable for sensors, supercapacitors, sensitizers, and electrocatalysts [28-31]. The first MPc-based ORR electrocatalyst dates back to 1964, in which Jasinski reported the catalytic activity of cobalt phthalocyanine ( $\mathrm{CoPc})$ in the cathode of fuel cells [32]. The catalytic properties of MPc are mainly governed by the central metal atoms, and their activity usually increases in the following order: copper, nickel, cobalt, and iron ( $\mathrm{Fe})$ [33]. Iron phthalocyanine $(\mathrm{FePc})$, which has the best ORR performance, a facile synthetic method, and a low cost, is considered to be one of the most promising Pt-free ORR catalysts (Figure 1C). In addition, variations in the chemical environment around FePc achieved by controlling the substituents on the Pc ligand can play important roles in determining the catalytic properties of FePc [34]. However, because FePc derivatives exhibit poor conductivity and undesirable aggregation, their catalytic performances are often inferior 
to those of Pt-based catalysts. To overcome these limitations, composite FePc-based electrocatalysts, in which FePc is immobilized on the surface of carbon-based materials, have been pioneered [35-39]. In these composite catalysts, the carbon-based not only improves the electrical conductivity and long-term stability, but also induces the uniform dispersion of FePc on the substrates. Graphene, a two-dimensional $\mathrm{sp}^{2}$-hybridized carbon sheet, is widely considered to be a promising supporter for the fabrication of composite catalysts because of its excellent electrical conductivity, large surface area, and good chemical and mechanical stability (Figure 1D) [37]. Because of the synergistic effects between the two constituents, FePc/graphene composite electrocatalysts exhibit great potential for the ORR. Herein, we summarize the recent progress in the development of FePc/graphene composite catalysts for the ORR. In addition, we discuss perspectives and important challenges in this promising field.

\section{Iron Phthalocyanine/Graphene Composite Catalysts for ORR}

\subsection{Noncovalent Approaches for Hybrid Catalysts}

Noncovalent methods are usually regarded as more versatile and promising for producing composite materials because the useful intrinsic properties of all constituents can be largely preserved. Generally, various driving forces, such as van der Waals forces, electrostatic forces, hydrogen bonding, and $\pi-\pi$ stacking interactions, have been employed for the noncovalent modification of graphene [40]. Noncovalent modification can easily take place over the entire graphene surface and is suitable for applications requiring high electrical conductivity. Interestingly, the planar aromatic structure of FePc enables it to easily adhere to the basal plane of graphene via the noncovalent $\pi-\pi$ stacking force; the high strength of $\pi-\pi$ stacking force between the two materials can induce the facile formation of stable composite materials [37]. In the composites, the graphene substrate can significantly improve the electron transfer process and the dispersion of FePc, thereby resolving the serious problems of aggregation and low conductivity found in FePc-based catalysts [41]. Together with pristine FePc and graphene, chemically functionalized FePc [42,43] and nitrogen-doped (n-doped) graphene [44] have also been utilized for the preparation of composite catalysts, with the aim of achieving enhanced ORR performances. The resulting composite catalysts exhibit superior ORR performances, excellent long-term stability, and good tolerance to methanol crossover and $\mathrm{CO}_{2}$ poisoning. Moreover, the additional advantages of FePc/graphene composites, which include low cost, easy preparation, and scalability to mass production, make them promising non-precious ORR electrocatalysts.

\subsubsection{FePc on Graphene}

First, Jiang et al. reported the synthesis of an efficient composite ORR catalyst, in which pristine FePc and reduced graphene oxide (RGO) were stacked together through $\pi-\pi$ stacking interactions (Figure 2Aa) [41]. The RGO used in this study was made through the mild thermal reduction of graphene oxide (GO) without any hazardous reducing agent. Subsequently, the mixture of RGO and FePc in dimethylformamide was stirred at room temperature and ultrasonicated to produce the target composite catalyst, denoted by g-FePc. As expected, the uniform dispersion of FePc aggregates with an average size of $40-50 \mathrm{~nm}$ on the surface of the RGO sheet was confirmed by transmission electron microscopy (TEM) image of g-FePc. Cyclic voltammetry (CV) measurements were conducted in a $0.1 \mathrm{M}$ $\mathrm{KOH}$ electrolyte to evaluate the ORR activity of g-FePc. As shown in Figure 2Ab, a prominent ORR peak at $-0.90 \mathrm{~V}$ with an enhanced current density was observed in $\mathrm{O}_{2}$-saturated electrolyte, while an almost flat smooth curve was observed in the $\mathrm{N}_{2}$-saturated electrolyte. This result clearly indicates the satisfactory ORR selectivity of g-FePc. In addition, linear sweep voltammetry (LSV) measurements revealed the superior catalytic ORR activity of g-FePc, compared to its individual components and to $\mathrm{FePc} / \mathrm{C}$ (Figure 2Ac). FePc/C was also a composite catalyst, in which FePc was mixed with the commercial Volcan XC-72 carbon. The transferred electron numbers $(n)$ of g-FePc, calculated from the Koutechky-Levich (K-L) plots, are 3.96, 3.97, and 4.00 at $0.35,0.25$, and $0.15 \mathrm{~V}$, respectively; 
this indicates that the g-FePc catalyst dominantly follows the favorable four-electron pathway during the ORR process under alkaline conditions. The synergistic effect of FePc and RGO through strong $\pi-\pi$ stacking interactions can result in the markedly enhanced ORR performance of g-FePc.

A (a)

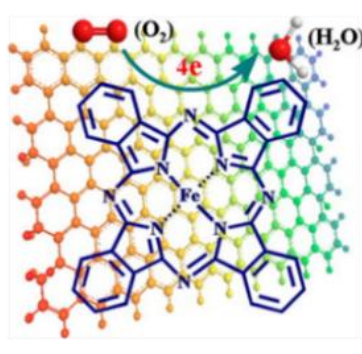

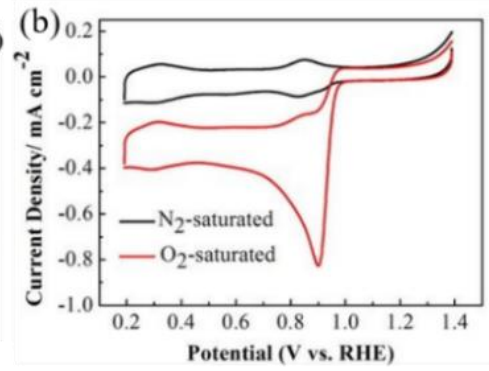

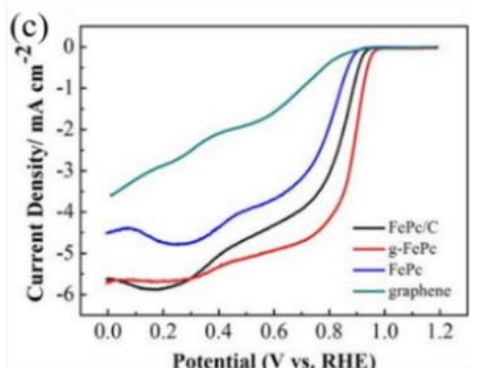

B

(a)
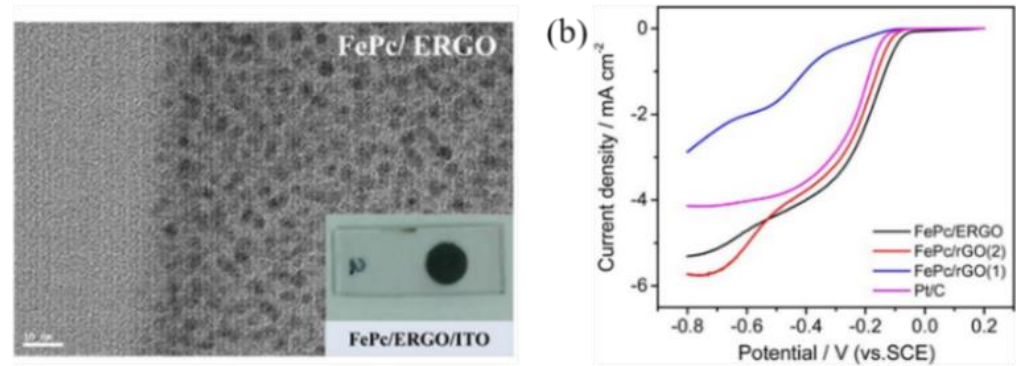

$\mathrm{C}$ (a)

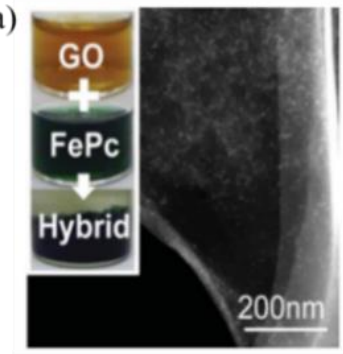

(b)

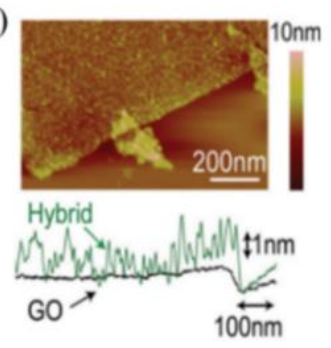

(c) $\widetilde{\tau}^{0.0} 0.1 \mathrm{M} \mathrm{KOH}$

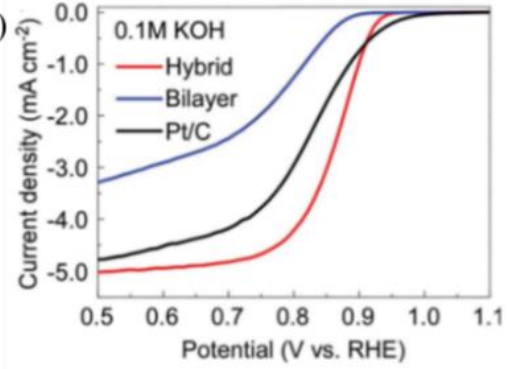

Figure 2. (A) (a) Schematic of the interaction between FePc and graphene, (b) CV curves of g-FePc in $\mathrm{N}_{2}$ - and $\mathrm{O}_{2}$-saturated $0.1 \mathrm{M} \mathrm{KOH}$ electrolyte at a scan rate of $10 \mathrm{mV} / \mathrm{s}$, and (c) linear sweep voltammetry (LSV) curves of FePc/C, g-FePc, FePc, and graphene in $\mathrm{O}_{2}$-saturated $0.1 \mathrm{M} \mathrm{KOH}$ electrolyte at $1600 \mathrm{rpm}$ adapted from ref [41] Copyright 2013 American Chemical Society. (B) (a) TEM image of FcPc/ERGO. The inset shows a photograph of the FcPc/ERGO film on the indium-tin-oxide glass. (b) LSV curves of $\mathrm{FcPc} / \mathrm{ERGO}, \mathrm{FcPc} / \mathrm{rGO}(1), \mathrm{FcPc} / \mathrm{rGO}(2)$, and $\mathrm{Pt} / \mathrm{C}$, adapted from ref [45] Copyright 2015 American Chemical Society. (C) (a) HAADA-STEM image of FePc/Go hydride with photographs of GO solution, FePc solution, and the precipitated FePc/Go hydride, and (b) LSV curve of FePc/Go hydride, FePc/Go bilayer, and $\mathrm{Pt} / \mathrm{C}$ in $0.1 \mathrm{M} \mathrm{KOH}$ electrolyte at $1600 \mathrm{rpm}$, adapted from ref [46] Copyright $2013 \mathrm{Wiley-VCH.}$

Similarly, Liu et al. reported the superior catalytic activity of an electrochemically reduced graphene oxide (ERGO)-supported FePc composite toward the ORR [45]. The target composite catalyst, named FePc/ERGO, was prepared by a two-step reaction in which a mixture of FePc and GO was first stirred for $6 \mathrm{~h}$ to create the FePc/GO precursor, then the precursor was reduced on the electrode using $\mathrm{CV}$ in the range of +0.2 to $-1.3 \mathrm{~V}$ for 20 cycles. Two composite samples, $\mathrm{FcPc} / \mathrm{rGO}(1)$ and $\mathrm{FcPC} / \mathrm{rGO}(2)$, were prepared simultaneously for comparison. The former was synthesized by thermal reduction of the $\mathrm{FePc} / \mathrm{GO}$ precursor, while the latter was produced by mixing thermally reduced RGO and FePc. The TEM image of the FePc/ERGO composite, shown in Figure 2Ba, displays a uniform dispersion of $\mathrm{FePc}$ nanoparticles with an average size of $3.5 \mathrm{~nm}$ on the surface of the graphene sheets. In addition, $\mathrm{FePc} / \mathrm{ERGO}$ can be readily deposited on the conductive substrates without using a binder (inset of Figure 2Ba); this is beneficial for the long-term durability of the catalytic activity and facile deposition on the electrode. After confirmation of the structural features of the composite catalysts, the ORR 
catalytic activities of the samples were analyzed by rotating disk electrode (RDE) measurements in an $\mathrm{O}_{2}$-saturated $0.1 \mathrm{M} \mathrm{KOH}$ electrolyte. The LSV curves of the samples, shown in Figure 2Bb, reveal the superior ORR activity of $\mathrm{FePc} / \mathrm{ERGO}$ with a positively shifted onset potential of $-0.015 \mathrm{~V}$. However, the onset potentials of $\mathrm{FCP} / \mathrm{rGO}(1)$ and $\mathrm{FcPC} / \mathrm{rGO}(2)$ were limited to -0.08 and $-0.04 \mathrm{~V}$, respectively. Notably, compared to commercial $\mathrm{Pt} / \mathrm{C}$, the FePc/ERGO catalyst exhibited enhanced performance with respect to most ORR properties, such as the onset potential, current density, $n$ value, methanol crossover, and long-term stability. These results indicate the usefulness of ERGO for producing high-performance FePc-based composite catalysts for the ORR.

Taniguchi et al. also demonstrated a self-assembly route for preparing a hybrid electrocatalyst composed of FePc and RGO to facilitate the ORR process [46]. During the preparation of the target composite, denoted by FePc/rGO, an ultrathin FePc layer was first self-assembled on the surface of GO through $\pi-\pi$ stacking interactions, then reduced electrochemically. The electrochemical reduction is usually regarded as a fast, clean, and nondestructive approach compared to conventional chemical reduction. The uniform distribution of FePc nanoclusters onto GO was confirmed by a high-angle annular dark-field scanning electron microscopy (HAADF-STEM) image, shown in Figure 2Ca. In addition, the atomic force microscopy (AFM) image of FePc/GO reveals that the thickness of the $\mathrm{FePc}$ nanodomains ranged from 0.4 to $1.5 \mathrm{~nm}$ (Figure $2 \mathrm{Cb}$ ). Therefore, the self-assembled FePc on the surface of graphene GO was composed of a single layer or a few layers. Moreover, the optimum $\mathrm{FePc} / \mathrm{GO}$ weight ratio in the hybrid catalyst was 5/1. A smaller ratio may lead to insufficient coverage of the FePc molecule on GO, while a higher ratio results in the formation of an undesirable thicker layer of FePc on GO. In both cases, the ORR activities of the composite catalyst can be significantly deteriorated. The ORR catalytic performance of the FePc/rGO hybrid was assessed by RDE linear sweep voltammograms in an $\mathrm{O}_{2}$-saturated $0.1 \mathrm{M} \mathrm{KOH}$ electrolyte. A bilayer sample, in which a thick layer of FePc was deposited on an electrode-bound layer of GO, was also prepared and tested to elucidate the effects of the thickness of the FePc layer on the ORR activity of the hybrid catalyst. As depicted in Figure 2Cc, the reduction current of the FePc/rGO hybrid in most Tafel regions became higher than those of the bilayer sample and commercial $\mathrm{Pt} / \mathrm{C}$. Interestingly, the $n$ number of $\mathrm{FePc} / \mathrm{rGO}$ exceeded 3.95 over the range of 0.2. to $0.9 \mathrm{~V}$; this number was also higher than those of the other samples. Together with the dominant four-electron reduction pathway, the $\mathrm{FePc} / \mathrm{rGO}$ hybrid catalyst exhibited excellent long-term operational stability. The self-assembly strategy used in this study is considered to be a promising approach to creating a high-performance ORR hybrid electrocatalyst, due to the ultrafast ORR kinetics and improved catalytic activities of the resultant FePc/rGO. Furthermore, this promising method can be extended to develop other functional carbon-based hybrid composite materials for emerging energy conversion and storage applications.

Recently, Wang et al. developed a well-defined composite catalyst, denoted by monolayer graphene (MLG)/FePc/Si, to exemplify encapsulated types of catalysts. In this configuration, the ORR active site of FePc was sandwiched between MLG and a Si substrate (Figure 3) [47]. This model catalyst was designed to investigate whether the surface carbon monolayer can be activated by the adjacent FePc molecule to facilitate the ORR process. As a reference, a FePc/MLG/Si catalyst, where the FePC molecule was located on the top MLG layer of the composite film, was also prepared. Interestingly, the ORR catalytic performances of the MLG/FePc/Si catalyst in $\mathrm{O}_{2}$-saturated $0.1 \mathrm{M} \mathrm{H}_{2} \mathrm{SO}_{4}$ electrolyte was comparable to that of the reference $\mathrm{FePc} / \mathrm{MLG} / \mathrm{Si}$. Because $\mathrm{O}_{2}$ molecules cannot be assessed directly to FePc molecules, the ORR activity of the MLG/FePc/Si catalyst can be attributed to the efficient activation of the surface carbon monolayer toward the ORR by the embedded FePc molecules. In addition, the $\mathrm{FePc} / \mathrm{MLG} / \mathrm{Si}$ catalyst was highly susceptible to $\mathrm{SCN}^{-}$poisoning tests, while $\mathrm{MLG} / \mathrm{FePc} / \mathrm{Si}$ was not sensitive to $\mathrm{SCN}^{-}$ions under the same conditions. This study highlights the usefulness of the encapsulated type ORR catalysts from the viewpoint of excellent tolerance to poisoning species, which can suppress the ORR activity of the catalyst. 


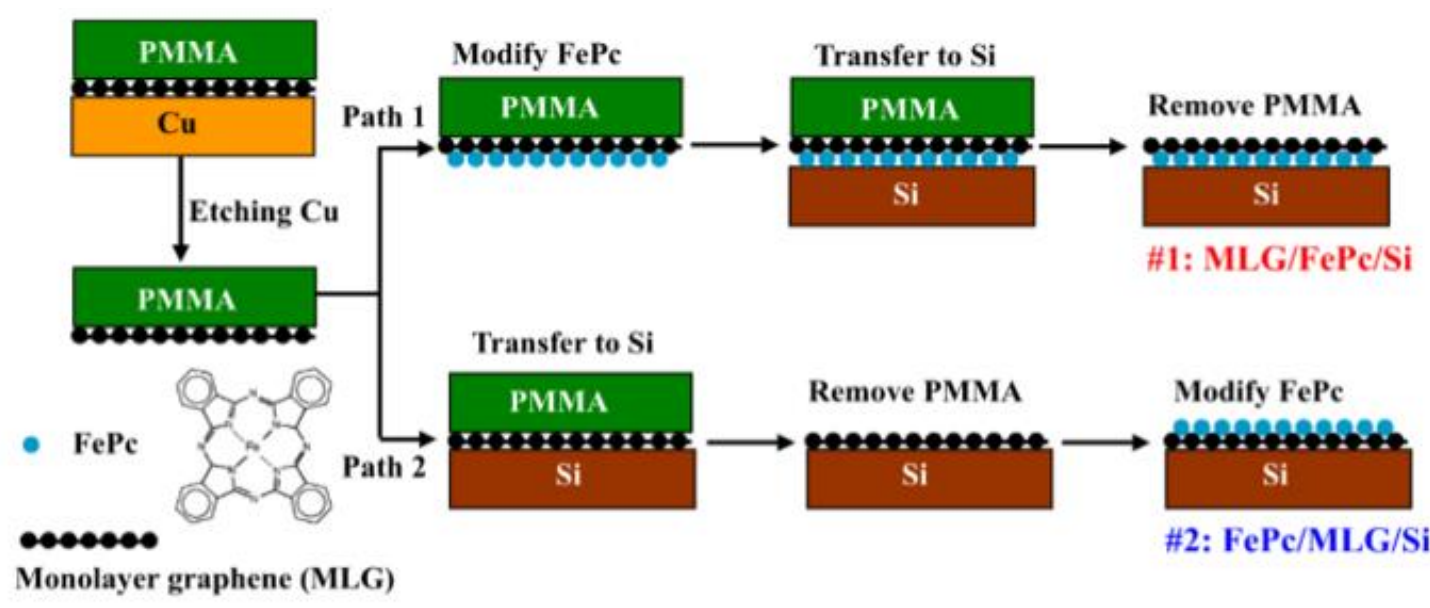

Figure 3. Schematic of the fabrication of monolayer graphene (MLG)/FePc/Si and FePc/MLG/Si, adapted from ref [47] Copyright 2020 Elsevier.

\subsubsection{Functionalized FePc on Graphene}

Generally, the peripheral substituents on the aromatic macrocycles of FePc can significantly tailor not only its physical and chemical properties, but also the electron density of the central iron atom [42]. These changes can also induce a strong influence on the ORR activity of FePc. Various functional groups have been incorporated into the periphery of the Pc ligand with the aim of improving the ORR activity of the resultant FePc-graphene composite catalysts. First, Yu et al. reported the development of a composite ORR catalyst composed of iron tetranitrophthalocyanine (FeTNPc) and poly(sodium- $p$-styrenesulfonate)-modified reduced graphene oxide (PSS-rGO). The FeTNPc/PSS-rGO composite was prepared by a solvothermal-assisted $\pi-\pi$ assembly approach (Figure 4Aa) [42]. The detailed synthesis route followed three consecutive steps; the TeTNPc and PSS-rGO were well-dispersed in dimethylformamide solution using ultrasonication, then the mixture was transferred to a Teflon-lined autoclave and placed into a convection oven at $160{ }^{\circ} \mathrm{C}$ for $12 \mathrm{~h}$. Once the reaction was completed, the composite catalyst was centrifuged and washed several times. For comparison, a composite catalyst composed of FeTNPc and activated carbon (AC), denoted by FeTNPc/AC, was also prepared under the same synthetic conditions. The mass ratio between the FeTNPc and the carbon supporters was optimized to $1 / 1$. Notably, the FeTNPc/PSS-rGO composite catalyst exhibited a more positive onset potential and higher current density during rotating ring disk electrode (RRDE) measurement compared with the commercial $\mathrm{Pt} / \mathrm{C}$ and FeTNPc/AC in $\mathrm{O}_{2}$-saturated $0.1 \mathrm{M}$ $\mathrm{KOH}$ electrolyte. (Figure $4 \mathrm{Ab}$ ). The $n$ values of the samples were calculated from the relationship between the disk and ring current of the RRDE curves; the values for FeTNPc/AC, FeTNPc/PSS-rGO, and $\mathrm{Pt} / \mathrm{C}$ were approximately 3.4, 3.9, and 4.0, respectively. In addition, FeTNPc/PSS-rGO exhibited the best long-term stability and tolerance to methanol crossover of all the samples. The superior ORR catalytic performance of FeTNPc/PSS-rGO may be induced by the synergistic effects between the two components. However, the role of peripheral nitrogen substituents on FePc should not be overlooked. They not only serve as additional active sites, but also decrease the electron density of the central iron atom, which can efficiently induce the enhanced $\mathrm{O}_{2}$ adsorption and ORR activity of the composite catalyst. 
A (a)
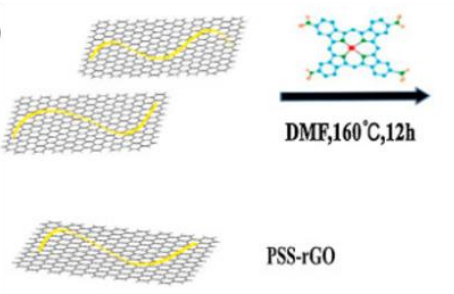

PSS-rG0

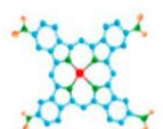

FeTNPc

B (a)

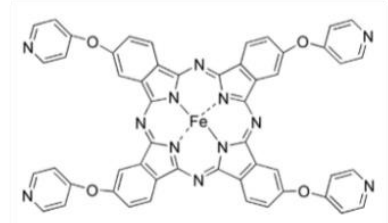

(b)
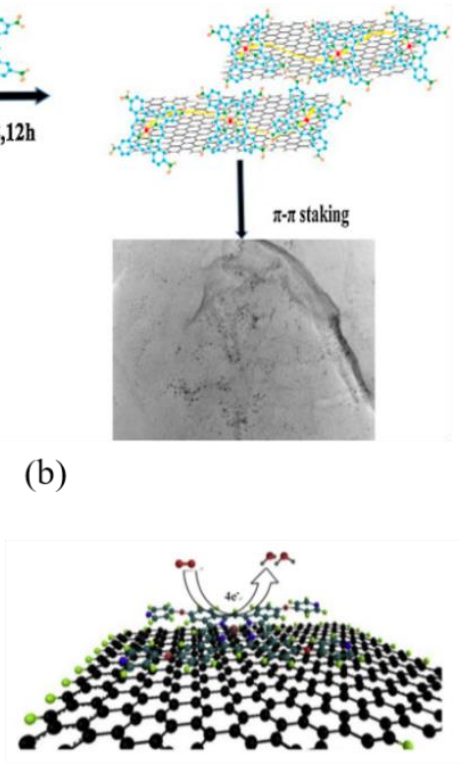

$\mathrm{C}(\mathrm{a})$

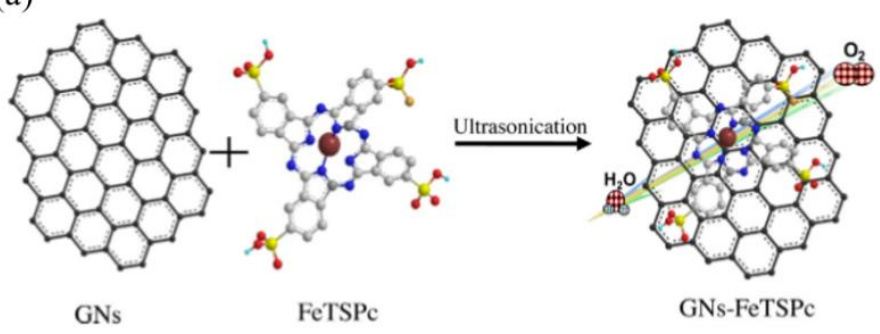

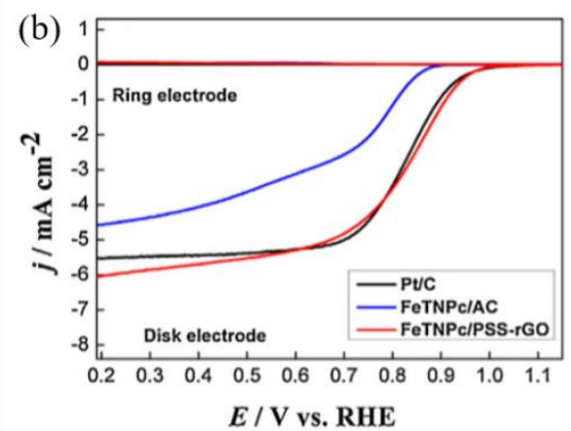

(c)

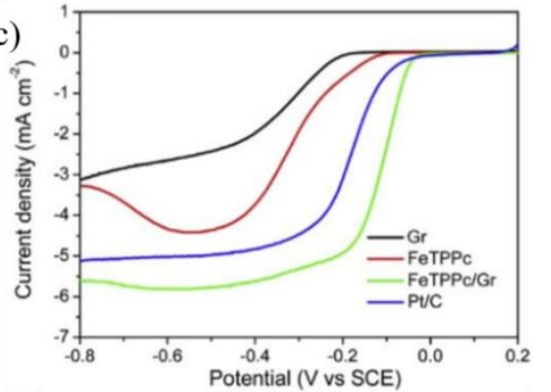

(b)

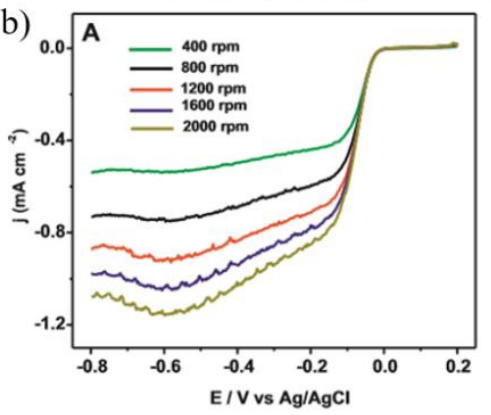

Figure 4. (A) Synthetic procedure for FeTNPc/PSS-rGO composites and (b) RRDE voltammograms of Pt/C, FeTNPc/AC, and FeTNPc/PSS-rGO, adapted from ref [42] Copyright 2016 Elsevier. (B) (a) Molecular structure of FeTPPc, (b) schematic of the four-electron oxygen reduction reaction (ORR) pathway on FeTPPc/Gr, and (c) RRDE voltammograms of FeTPPc/Gr and Pt/C, adapted from ref [43] Copyright 2015 Elsevier. (C) (a) Illustration of GNs-FeTsPC via the $\pi-\pi$ stacking interaction, and (b) LSV curves of GNs-FeTsPC in air-saturated $0.1 \mathrm{M} \mathrm{KOH}$ electrolyte at different rotation speeds, adapted from ref [48] Copyright 2014 Elsevier.

Second, Cui et al. demonstrated the synthesis of an iron tetrapyridyloxyphthalocyanine (FeTPPc)-decorated graphene (FeTPPc/Gr) composite ORR catalyst using a solvothermal-assisted $\pi-\pi$ assembly approach [43]. Motivated by the excellent ORR activity of pyridinic nitrogen frequently observed in n-doped graphene derivatives, Cui et al. incorporated four pyridine units into the peripheral macrocycles of $\mathrm{FePc}$ (Figure $4 \mathrm{Ba}$ ). In the $\mathrm{CV}$ measurements, a clear oxygen reduction peak around $-0.118 \mathrm{~V}$ was observed for FeTPPc/Gr in an $\mathrm{O}_{2}$-saturated $0.1 \mathrm{M} \mathrm{NaOH}$ electrolyte. The current density of the FeTPPc/Gr composite catalyst was maximized at a weight ratio of $1 / 1$. The $n$ values of the samples were also analyzed using the well-known K-L plot; the electrocatalytic ORR process of FeTPPc/Gr followed a one-step four-electron pathway along almost the entire potential range (Figure 4Bb). Interestingly, the synergistic effects between FeTPPc and graphene improved ORR activity on FeTPPc/Gr compared with the individual component (Figure 4Bc). Moreover, while maintaining excellent long-term stability and tolerance to methanol crossover, the FeTPPc/Gr composite catalyst exhibited a more positive onset potential, half-wave potential, and higher current density than the commercial Pt/C catalyst. The enhanced ORR performance of the FeTPPc/Gr catalyst is attributed to the positive contributions of the pyridine substituents in FeTPPc, such as providing additional catalytic sites and facilitating $\mathrm{O}_{2}$ adsorption and ORR activity. 
Finally, Gao et al. utilized iron tetrasulfophthalocyanine (FeTSPc) and graphene nanosheets (GNs) to produce a high-performance ORR composite catalyst named GNs-FeTSPc (Figure 4Ca) [48]. Although FeTSPc possesses a promising potential to catalyze the ORR process under alkaline conditions, its direct utilization in the ORR catalyst is almost impossible because of its extremely good water solubility. During operation, FeTSPc molecules can be readily removed from the surface of the electrode. Therefore, the fabrication of the composite catalyst with FeTSPc and GNs can be regarded as a desirable approach not only for solving the solubility problem, but also for utilizing the superb ORR activity of FeTSPc. FeTSPc molecules are readily coated onto the surface of GNs during the simple ultrasonication process. The superior hydrophilic nature of FeTSPc molecules can prevent the undesirable aggregation of GNs. The resultant GNs-FeTSPc displays satisfactory long-term stability in alkaline electrolytes and outstanding resistance against $\mathrm{CO}$ and methanol crossover. In addition, the ORR activity of GNs-FeTSPc follows a promising one-step four-electron process, which was confirmed by kinetic studies using LSV curves at rotation speeds from 400 to $2000 \mathrm{rpm}$ (Figure 4Cb). Furthermore, the catalytic properties of GNs-FeTSPc outperform those of the commercial Pt/C catalyst, indicating the significant effects of FeTSPc on promoting the ORR activity of the composite catalyst. Because of the positive contributions of polar substituents, such as nitro, pyridine, and sulfonate groups, at the periphery of FePc, significant improvement in the ORR activity was achieved from the hybrid composite catalysts composed of functionalized FePcs and graphene. These functional groups in the composite catalyst often play dual roles as additional ORR active sites and as promoters of ORR activity by controlling the electronic structures of the adsorbed FePc molecules.

\subsubsection{FePc on Nitrogen-Doped Graphene}

Nitrogen-doped graphene (NG) has emerged as a particularly promising alternative metal-free ORR catalyst because of its prominent catalytic activity, large surface area, and excellent dimensional stability [6]. When NG is adopted as a conductive substrate in FePc-based catalysts, rather than non-doped graphene, a significant enhancement in the ORR activities of the hybrid catalyst can be anticipated. In this regard, Zhang et al. verified the usefulness of NG as a conductive substrate for fabricating FePc-based hybrid catalysts by comparing the ORR activity of three composite catalysts with different types of graphene, such as NG, GO, and rGO [44]. Three representative composite catalysts, denoted as $\mathrm{FePc} / \mathrm{NG}, \mathrm{FePc} / \mathrm{GO}$, and $\mathrm{FePc} / \mathrm{rGO}$, were prepared using simple ultrasonication for $1 \mathrm{~h}$. FePc/NG exhibited the best ORR catalytic performance, with the highest onset potentials and the largest current densities, in addition to excellent tolerance to methanol crossover. These greatly improved ORR activities of FePc/NG were induced by the merits of using NG as a conductive substrate in the composite catalyst, such as high electrical conductivity and large populations of ORR active sites.

Notably, Yin et al. prepared a three-dimensional (3D) NG aerosol-supported iron nitride $\left(\mathrm{Fe}_{\mathrm{x}} \mathrm{N}\right)$ nanoparticle $\left(\mathrm{Fe}_{\mathrm{x}} \mathrm{N} / \mathrm{NGA}\right)$ composite as an efficient ORR catalyst using a simple two-step process (Figure 5Aa) [49]. In the first step, FePc molecules were uniformly dispersed and anchored on the surface of GO via $\pi-\pi$ interactions; then, the mixture was treated by a hydrothermal process to produce the FeN/NGA intermediate. Subsequently, the target composite of $\mathrm{Fe}_{x} \mathrm{~N} / \mathrm{NGA}$ was obtained by lyophilization and annealing of FeN/NGA in an $\mathrm{NH}_{3}$ atmosphere at $700^{\circ} \mathrm{C}$. Additionally, the individual components of $\mathrm{Fe}_{\mathrm{x}} \mathrm{N}$ and NGA, without the addition of $\mathrm{GO}$ and FePc during the hydrothermal process, respectively, were separately prepared. In the $\mathrm{CV}$ analysis, the 3D hybrid exhibited a remarkable ORR peak at $-0.12 \mathrm{~V}$ in an $\mathrm{O}_{2}$-saturated $0.1 \mathrm{M} \mathrm{KOH}$ electrolyte, while an almost smooth featureless curve was obtained from the $\mathrm{N}_{2}$-saturated condition, indicating its excellent ORR selectivity (Figure $5 \mathrm{Ab}$ ). Compared with those of $\mathrm{Pt} / \mathrm{C}$, the onset potential and current density of the ORR peak from the $\mathrm{Fe}_{x} \mathrm{~N} / \mathrm{NGA}$ composite were more favorable. To further investigate the ORR activity of $\mathrm{Fe}_{\mathrm{x}} \mathrm{N} / \mathrm{NGA}$, RDE measurements of the samples were carried out in an $\mathrm{O}_{2}$-saturated $0.1 \mathrm{M} \mathrm{KOH}$ electrolyte. The results are summarized in Figure 5Ac. Interestingly, the polarization curve of $\mathrm{Fe}_{x} \mathrm{~N} / \mathrm{NGA}$ was almost similar to that of the $\mathrm{Pt} / \mathrm{C}$ catalyst, indicating the satisfactory ORR activity of the newly developed $3 \mathrm{D}$ composite catalyst. In comparison, the individual components of $\mathrm{Fe}_{\mathrm{x}} \mathrm{N}$ and NGA 
showed relatively poor ORR activity under the same conditions. The simple physical mixture of the two individual components did not show any enhancement to catalytic activity. Therefore, the strong and synergistic interactions between $\mathrm{Fe}_{\mathrm{x}} \mathrm{N}$ and NGA are crucial for the remarkable ORR activity of the $3 \mathrm{D}$ composite catalyst, $\mathrm{Fe}_{\mathrm{x}} \mathrm{N} / \mathrm{NGA}$.

A (a)

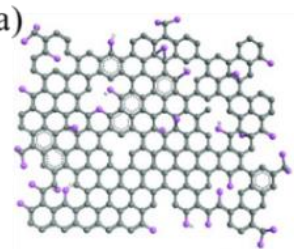

Graphene Oxide

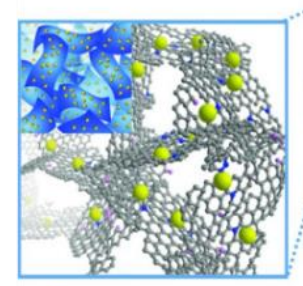

OFe.N FexN/NGA

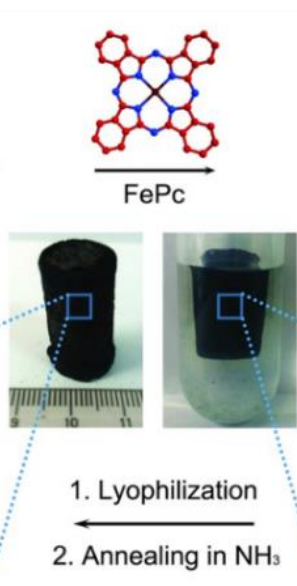

2. Annealing in $\mathrm{NH}_{3}$

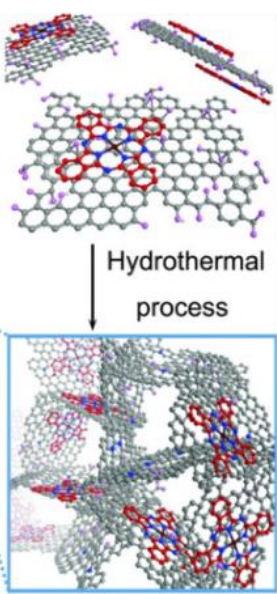

$\mathrm{FePc} / \mathrm{NGA}$

(b)

(c)

(b)

$\mathrm{B}(\mathrm{a})$

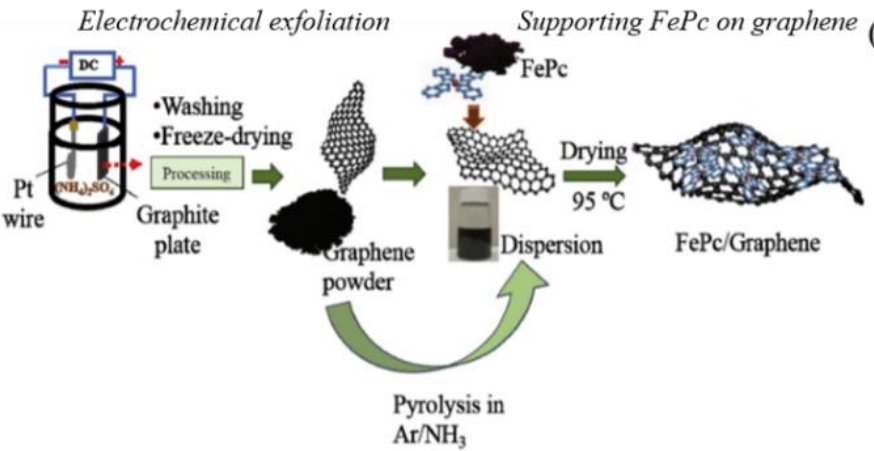

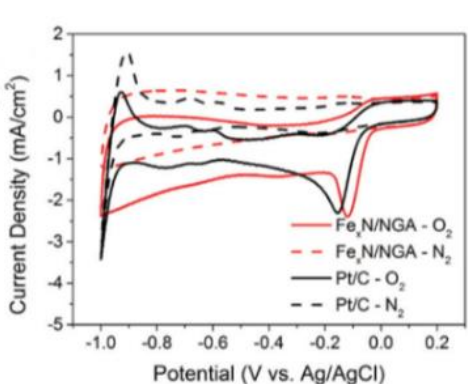
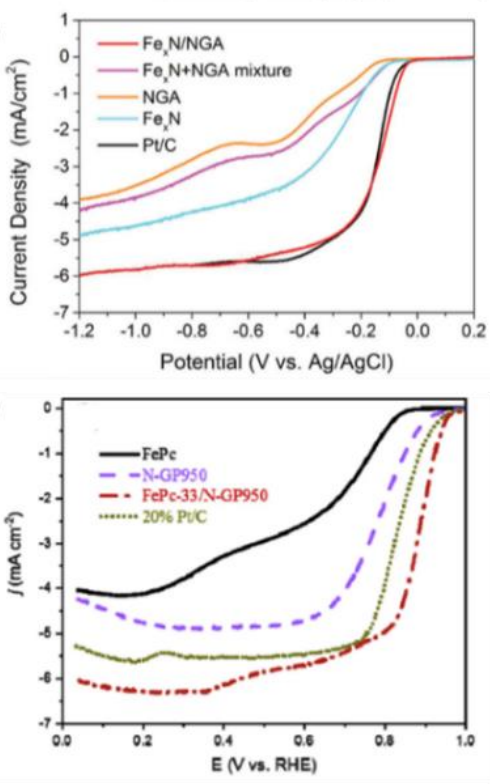

Figure 5. (A) (a) Schematic of the preparation of the $\mathrm{Fe}_{x} \mathrm{~N} / \mathrm{NGA}$ catalyst, (b) CV curves of $\mathrm{Fe}_{x} \mathrm{~N} / \mathrm{NGA}$ and $\mathrm{Pt} / \mathrm{C}$ in $\mathrm{O}_{2}$-saturated and $\mathrm{N}_{2}$-saturated $0.1 \mathrm{M} \mathrm{KOH}$ electrolyte, and (c) LSV curves of all samples in $\mathrm{O}_{2}$-saturated electrolyte at $1600 \mathrm{rpm}$, adapted from ref [49] Copyright 2014 Wiley-VCH. (B) (a) SchBematic view of the preparation of the FePC/N-GP950 catalyst, and (b) LSV curves of FePc, N-GP950, $\mathrm{FePc} / \mathrm{N}-\mathrm{GP} 950$, and $\mathrm{Pt} / \mathrm{C}$ catalyst in $\mathrm{O}_{2}$-saturated $0.1 \mathrm{M} \mathrm{KOH}$ electrolyte at $1600 \mathrm{rpm}$, adapted from ref [50] Copyright 2019 Elsevier.

Recently, Komba et al. fabricated a composite catalyst in which FePc was immobilized onto a surface of $n$-doped electrochemically exfoliated graphene (N-GP950) [50]. The electrochemical exfoliation process is considered to be a low-cost, fast, scalable, and eco-friendly method for producing high-quality graphene sheets. As depicted in Figure 5Ba, N-GP950 was prepared by the pyrolysis of electrochemically exfoliated graphene under an $\mathrm{Ar} / \mathrm{NH}_{3}$ atmosphere. Then the prepared N-GP950 was mixed with FePc, with the formation of the target FePc/N-GP950 composite catalyst Because of its unique morphological and compositional features, the FePc/N-GP950 catalyst exhibited outstanding ORR activity, with superior onset potential ( $0.97 \mathrm{~V}$ vs. RHE), half-wave potential ( $0.89 \mathrm{~V}$ vs. RHE), and current density at $0.8 \mathrm{~V}\left(5.0 \mathrm{~mA} \mathrm{~cm}^{-2}\right)$ in $0.1 \mathrm{M} \mathrm{KOH}$ electrolyte, compared with the individual components and $20 \% \mathrm{Pt} / \mathrm{C}$ (Figure $5 \mathrm{Bb}$ ). In addition, extraordinary long-term stability without any appreciable reduction in activity even after 5000 cycles was observed for FePc/N-GP950. Overall, the utilization of an n-doped graphene substrate can be regarded as one of the most promising strategies for enhancing the ORR activity of the FePc/graphene composite catalyst. 


\subsection{Covalent Approaches for Hybrid Electrocatalysts}

Although the noncovalent approach based on the strong $\pi-\pi$ stacking interactions between $\mathrm{FePc}$ and graphene is beneficial for preserving their intrinsic properties in the composite catalysts, its practical application still suffers from low loading levels and insufficient long-term stability of FePc molecules on the graphene surface. However, specified FePc molecules with functional groups can be readily anchored onto the edge and basal plane of graphene via covalent bonds. In this condition, although the intrinsic conductivity of graphene can be compromised by the formation of covalent bonds, more intimate interactions between $\mathrm{FePc}$ and graphene occur with the enhanced structural stability of the composite. Herein, we focus on the recent advances in covalently functionalized hybrid composite catalysts between FePc and graphene for the ORR.

\subsubsection{Amide Linkage between FePc and Graphene}

Liu et al. developed a composite catalyst in which FePc molecules are covalently linked to a graphene (Gr) substrate through amide linkage [51]. A condensation reaction between the amine groups in iron tetraaminophthalocyanine (FeTAPc) and carboxylic acid moieties in carboxylic-functionalized graphene oxide (CFGO) was first carried out to prepare intermediate hybrid materials decorated with amide linkages. Subsequently, the reduction reaction of the intermediate materials using hydrazine hydrate produced the target composite catalyst (FePc-Gr). The overall synthetic route of FePc-Gr is outlined in Figure 6A. The successful incorporation of FePc units on the graphene surface via amide linkage was confirmed by various structural analyses, such as scanning electron microscopy, TEM, and X-ray photoelectron spectroscopy. To investigate the electrocatalytic activity of FePc-Gr during the ORR process, $\mathrm{RDE}$ measurements were conducted in an $\mathrm{O}_{2}$-saturated $0.1 \mathrm{M} \mathrm{NaOH}$ electrolyte. As depicted in Figure $6 \mathrm{~B}$, the ORR peak of FeTAPc itself starts at $-0.128 \mathrm{~V}$ in the polarization curve, while the onset potential of the FePc-Gr composite is positively shifted to $-0.018 \mathrm{~V}$. This value is even better than that of the commercial $\mathrm{Pt} / \mathrm{C}$ catalyst $(-0.075 \mathrm{~V})$. In addition, the current density of the FePc-Gr composite catalyst becomes higher than that of FeTAPc and is almost comparable to that of Pt/C. The $n$ values for the ORR process of FePc-Gr, FeTAPc, and Pt/C catalyst were calculated from the K-L plot, and the results are shown in Figure 6C. The $n$ values of FePc-Gr ranged from 3.99 to 4.44 , indicating that the FePc-Gr catalyst follows the favorable four-electron pathway during the ORR process. On the other hand, the $n$ values of FeTAP are limited to a range of 2.99 to 3.64 in the same condition, pointing out the coexistence of two-electron and four-electron pathways in its ORR mechanisms. Moreover, the FePc-Gr composite catalyst displayed higher tolerance to methanol crossover and better long-term stability compared to $\mathrm{Pt} / \mathrm{C}$. In summary, the application of the covalent linkage between FePc and graphene can lead to significant improvement in the catalytic performance of the composite catalyst toward the ORR in alkaline media; this is attributed to the close and synergistic interactions between the two components.

\subsubsection{Fe-O-C Linkage between FePc and Graphene}

Guo et al. reported the development of a high-performance hybrid composite catalyst in which FePc molecules with different valence states were covalently anchored on the surface of RGO through a Fe-O-C linkage [52]. To synthesize the target composite, FePc perchlorate precursors were first reacted with GO under axial covalent conditions; then, the obtained FePc/GO composites were further reduced in the presence of $\mathrm{NaNH}_{4}$ and hydrazine hydrate as reducing agents (Figure 7). The resulting axial complex, denoted by $\mathrm{Fe}(\mathrm{II}) \mathrm{Pc} / \mathrm{Fe}(\mathrm{III}) \mathrm{Pc} / \mathrm{RGO}$, was produced via Fe-O-C linkage of between FePc and RGO and applied as the ORR electrocatalyst. The molar ratio of FePc to the graphene substrate was carefully controlled to optimize the ORR activity of the composite catalyst. In addition, the coexistence of $\mathrm{Fe}(\mathrm{II}) \mathrm{Pc}$ and $\mathrm{Fe}(\mathrm{III}) \mathrm{Pc}$ in the composite was confirmed by X-ray absorption near edge structure spectra; this coexistence can induce a synergistic catalytic effect because of the strong dependence of the ORR activity of the composite catalyst on the dynamic structures of $\mathrm{Fe}^{2+} / \mathrm{Fe}^{3+}$. Moreover, the axial 
coordination between FePc and RGO via Fe-O-C linkage can not only prohibit the aggregation and deformation of FePc molecules, but also improve the conductivity and stability of the composite. Consequently, compared with the commercial Pt/C catalyst, the optimized $\mathrm{Fe}(\mathrm{II}) \mathrm{Pc} / \mathrm{Fe}(\mathrm{III}) \mathrm{Pc} / \mathrm{RGO}$ catalyst exhibited superior ORR performance in terms of onset potential, half-wave potential, and durability in alkaline electrolyte.

Koh et al. prepared covalently functionalized graphene quantum dots (GQDs) with FePc using a simple ferric chloride reaction [53]. As illustrated in Figure 8Aa,b, the conjugation of GQDs with FePc in the composite was achieved by the formation of Fe-O-C bonds between them. In addition, the average lateral size of the GQD-FePc composite $(3.77 \mathrm{~nm})$ was larger than that of the pristine GQDs $(2.76 \mathrm{~nm}$ ) upon successful covalent hybridization (Figure 8Ac,d). As depicted in Figure 8Ba, the LSV curves at $1600 \mathrm{rpm}$ in an $\mathrm{O}_{2}$-saturated $0.1 \mathrm{M} \mathrm{KOH}$ electrolyte reveal a clear comparison of the ORR activity between the samples. The onset potential and limiting current of the pristine GQDs are limited to $-0.13 \mathrm{~V}$ and $-1.65 \mathrm{~mA} / \mathrm{cm}^{2}$, respectively, while those of the GQD-FePc composite are significantly improved to $-0.04 \mathrm{~V}$ and $-4.68 \mathrm{~mA} / \mathrm{cm}^{2}$, respectively. These enhanced ORR activities of the composite catalyst can be attributed to the faster charge transfer and synergistic effects between FePc and GQDs. The $n$ values of the samples were estimated from the K-L equation, and the results are shown in Figure 8Bb. Interestingly, GQD-FePc exhibits a promisingly high average $n$ value of 3.80, indicating the dominant four-electron pathway for the ORR. The $n$ value of the composite catalyst is almost comparable to that of the $\mathrm{Pt} / \mathrm{C}$ catalyst (3.77). In addition, GQD-FePc exhibits the additional advantages of prolonged electrochemical stability and notable tolerance to methanol crossover and $\mathrm{CO}$ poisoning. Overall, the covalently functionalized GQD-FePc composite exhibits good potential as a non-precious electrocatalyst for the ORR.
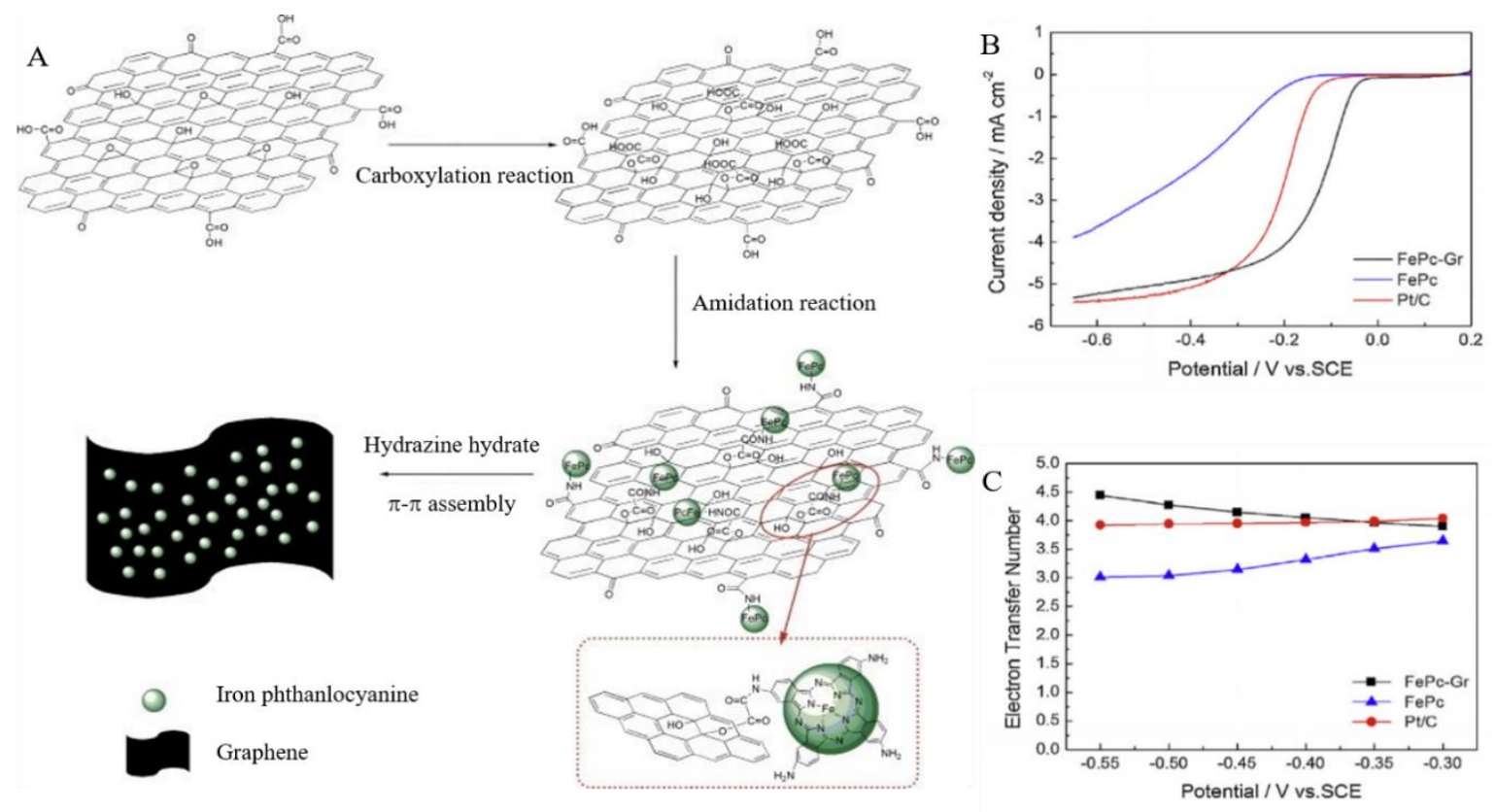

Figure 6. (A) The synthetic route of the FePc-Gr composite catalyst, (B) LSC curves of FePc-Gr, FePC, and $\mathrm{Pt} / \mathrm{C}$ in $\mathrm{O}_{2}$-saturated $0.1 \mathrm{M} \mathrm{NaOH}$ at a scan rate of $10 \mathrm{mVs}^{-1}$, and (C) the number of electrons transferred at different potentials of FePc-Gr, FePC, and $\mathrm{Pt} / \mathrm{C}$ adapted from ref [51] Copyright 2013 Elsevier. 


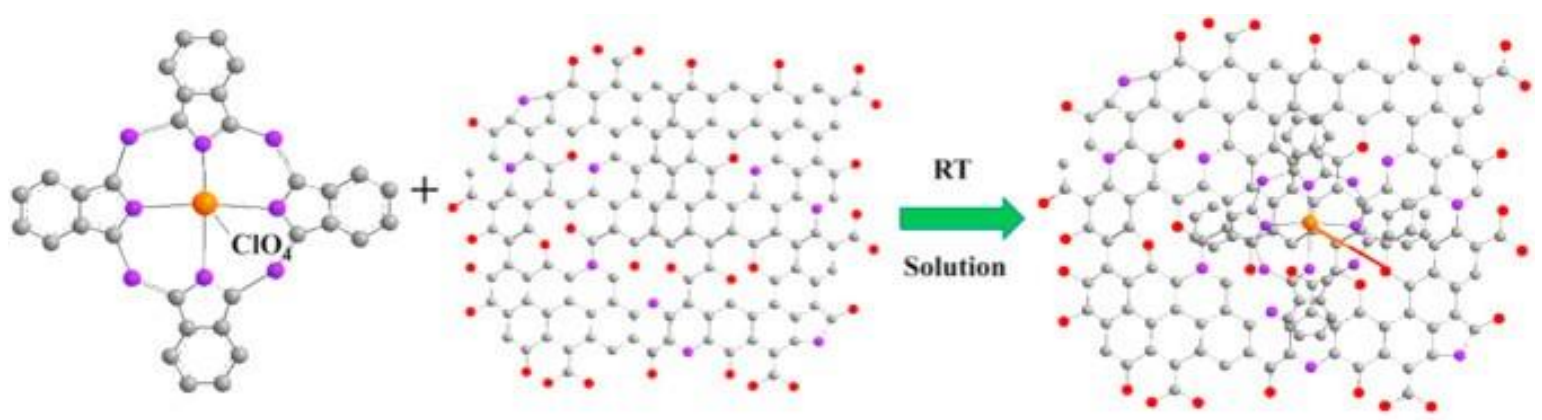

$\mathrm{FePc}^{+} . \mathrm{ClO}_{4}^{-}$/acetonitrile Graphene Oxide/Water

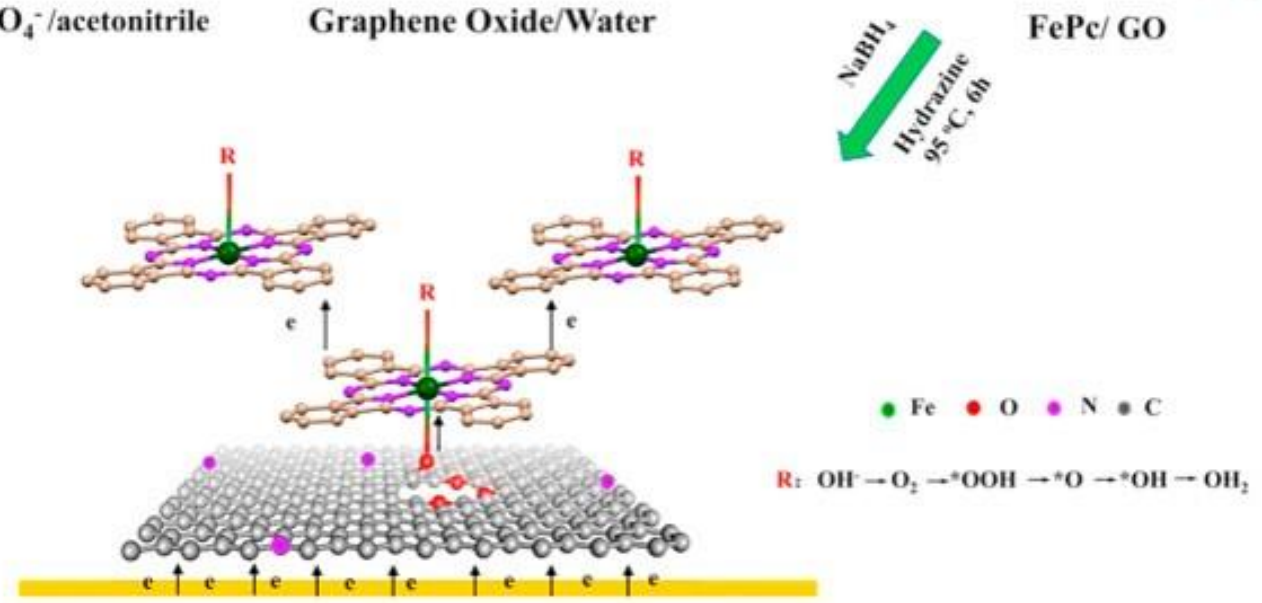

$\mathrm{Fe}(\mathrm{II}) \mathrm{Pc} / \mathrm{Fe}(\mathrm{III}) \mathrm{Pc} / \mathrm{RGO}$ and ORR

Figure 7. Schematics of the synthesis and catalytic ORR mechanism of Fe(II)Pc/Fe(III)Pc/RGO adapted from ref [52] Copyright 2018 Elsevier.

A (a)

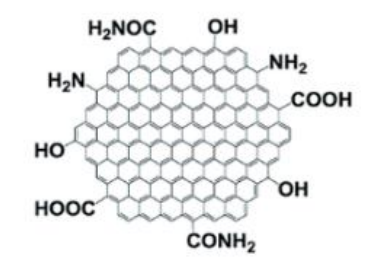

(c)

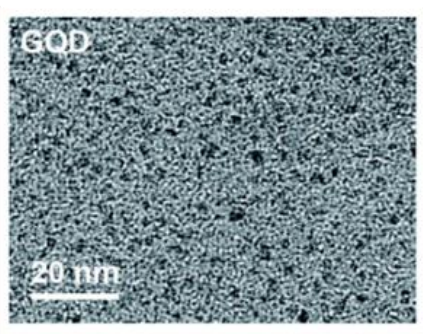

(b)

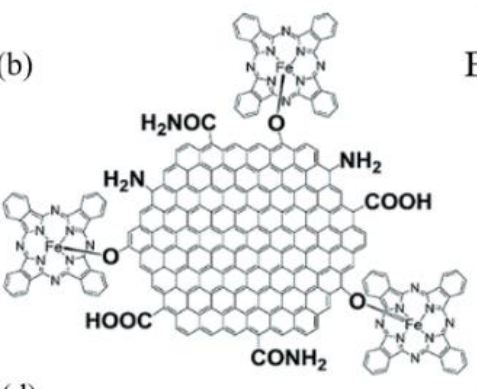

(d)

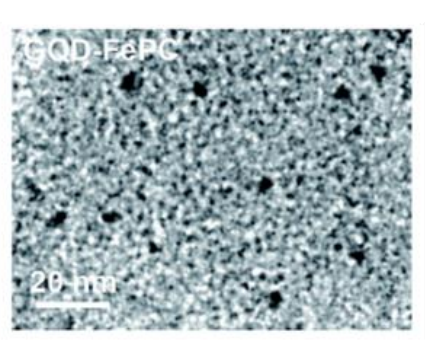

B (a)

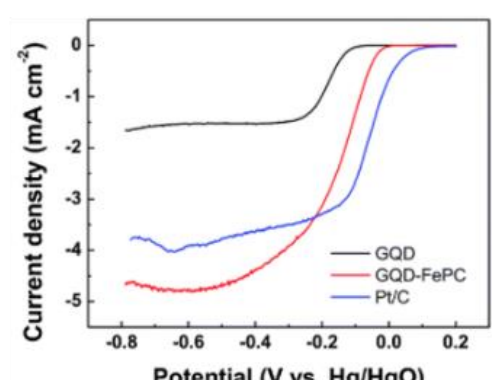

(b)

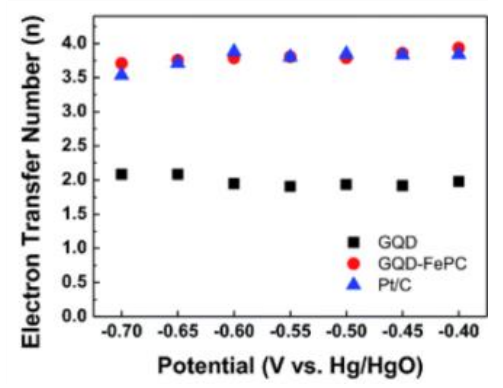

Figure 8. Chemical structures of (A) (a) graphene quantum dots (GQD) and (b) GQD-FePc. TEM images of (c) GQD and (d) GQD-FePC. (B) (a) LSC curves at $1600 \mathrm{rpm}$ and (b) the electron transferred numbers of GQD, GQD-FePc, and $\mathrm{Pt} / \mathrm{C}$ in $\mathrm{O}_{2}$-saturated $0.1 \mathrm{M} \mathrm{KOH}$ electrolyte adapted from ref [53] Copyright 2017 Royal Society of Chemistry. 


\section{Conclusion and Outlook}

In this review article, recent developments related to hybrid ORR catalysts composed of FePc and graphene have been discussed. Some noticeable achievements are summarized in Table 1. There is a strong demand to replace the currently used expensive Pt-based materials with non-precious high performance ORR electrocatalysts, in order to sustainably commercialize DMFC technologies. In this regard, various kinds of FePc and graphene derivatives have been utilized and combined during the preparation of hybrid catalysts. Owing to their facile synthetic protocols and satisfactory catalytic performances, $\mathrm{FePc} / g r a p h e n e$ composites have emerged as promising alternatives to commercial Pt-based electrocatalysts for the ORR. Two distinct methods, noncovalent and covalent modification, can be considered for the preparation of hybrid composites with FePc and graphene. The former is more versatile and suitable for maintaining the intrinsic properties of both components, while the latter can induce closer mutual interactions through the strong covalent bonds between FePc and graphene. Despite impressive progress up to now, research in the related field is still in its infancy.

Table 1. Summary of FePc/graphene composite catalysts for the ORR.

\begin{tabular}{|c|c|c|c|c|c|}
\hline \multirow{2}{*}{ Interaction } & \multicolumn{2}{|c|}{ Materials } & \multirow{2}{*}{$\begin{array}{l}\text { Main Driving } \\
\text { Force }\end{array}$} & \multirow{2}{*}{ Remark } & \multirow{2}{*}{ Ref. } \\
\hline & Phthalocyanine & Graphene & & & \\
\hline \multirow{10}{*}{ Noncovalent } & FePc & $\mathrm{RGO}^{\mathrm{a}}$ & $\pi-\pi$ stacking & $\begin{array}{c}\text { ORR peak at } 0.90 \mathrm{~V} \text { vs. } \text { RHE }^{\mathrm{b}} \\
n=3.97,0.1 \mathrm{M} \mathrm{KOH}\end{array}$ & 41 \\
\hline & $\mathrm{FePc}$ & ERGO $^{c}$ & $\pi-\pi$ stacking & $\begin{array}{c}\text { ORR peak at }-0.15 \mathrm{~V} \text { vs. SCE }{ }^{\mathrm{d}} \\
n=3.93,0.1 \mathrm{M} \mathrm{KOH}\end{array}$ & 45 \\
\hline & $\mathrm{FePc}$ & ERGO & $\pi-\pi$ stacking & $\begin{array}{c}\text { ORR peak at }-0.08 \mathrm{~V} \text { vs. SCE } \\
n=3.95,0.1 \mathrm{M} \mathrm{KOH}\end{array}$ & 46 \\
\hline & $\mathrm{FePc}$ & MLG $^{\mathrm{e}}$ & $\pi-\pi$ stacking & $\begin{array}{c}\text { ORR peak at } 0.65 \mathrm{~V} \text { vs. RHE } \\
0.1 \mathrm{M} \mathrm{KOH}\end{array}$ & 47 \\
\hline & FeTNPc ${ }^{f}$ & PSS-rGO $^{g}$ & $\pi-\pi$ stacking & $\begin{array}{c}\text { ORR peak at } 0.86 \mathrm{~V} \text { vs. RHE } \\
n \sim 4.0,0.1 \mathrm{M} \mathrm{KOH}\end{array}$ & 42 \\
\hline & FeTPPc ${ }^{h}$ & PSS-rGO & $\pi-\pi$ stacking & $\begin{array}{c}\text { ORR peak at }-0.12 \mathrm{~V} \text { vs. SCE } \\
n=3.92,0.1 \mathrm{M} \mathrm{NaOH}\end{array}$ & 43 \\
\hline & FeTSPc $^{\mathrm{i}}$ & RGO & $\pi-\pi$ stacking & $\begin{array}{c}\text { ORR peak at }-0.05 \mathrm{~V} \text { vs. SCE } \\
n \sim 3.75,0.1 \mathrm{M} \mathrm{KOH}\end{array}$ & 48 \\
\hline & $\mathrm{FePc}$ & $\mathrm{NG}^{\mathrm{j}}$ & $\pi-\pi$ stacking & $\begin{array}{c}\text { ORR peak at }-0.01 \mathrm{~V} \text { vs. SCE } \\
n \sim 4.0,0.1 \mathrm{M} \mathrm{KOH}\end{array}$ & 44 \\
\hline & $\mathrm{FePc}$ & $\mathrm{NGA}^{\mathrm{k}}$ & $\pi-\pi$ stacking & $\begin{array}{c}\text { ORR peak at }-0.12 \mathrm{~V} \text { vs. SCE } \\
n \sim 4.0,0.1 \mathrm{M} \mathrm{KOH}\end{array}$ & 49 \\
\hline & $\mathrm{FePc}$ & N-GP950 ${ }^{1}$ & $\pi-\pi$ stacking & $\begin{array}{c}\text { ORR peak at } 0.97 \mathrm{~V} \text { vs. RHE } \\
n=3.99,0.1 \mathrm{M} \mathrm{KOH}\end{array}$ & 50 \\
\hline \multirow{3}{*}{ Covalent } & FeTAPc $^{m}$ & RGO & Amide bond & $\begin{array}{c}\text { ORR peak at }-0.12 \mathrm{~V} \text { vs. SCE } \\
n \sim 4.0,0.1 \mathrm{M} \mathrm{KOH}\end{array}$ & 51 \\
\hline & $\mathrm{FePc}, \mathrm{ClO}_{4}$ & RGO & Fe-O-C bond & $\begin{array}{c}\text { ORR peak at } 1.00 \mathrm{~V} \text { vs. RHE } \\
n \sim 4.0,0.1 \mathrm{M} \mathrm{KOH}\end{array}$ & 52 \\
\hline & $\mathrm{FePc}$ & $\mathrm{GQD}^{\mathrm{n}}$ & Fe-O-C bond & $\begin{array}{c}\text { ORR peak at }-0.10 \mathrm{~V} \text { vs. } \mathrm{Hg} / \mathrm{HgO}, \\
n=3.80,0.1 \mathrm{M} \mathrm{KOH}\end{array}$ & 53 \\
\hline
\end{tabular}

\footnotetext{
a RGO: Reduced graphene oxide. b RHE: Reversible hydrogen electrode. c ERGO: Electrochemically reduced graphene oxide. d SCE: Saturated calomel electrode. e MLG: Monolayer graphene. f FeTNPc: Iron tetranitrophthalocyanine. g PSS-rGO: Poly(sodium- $p$-styrenesulfonate) modified reduced graphene oxide. ${ }^{h}$ FeTPPc: Iron tetrapyridyloxyphthalocyanine. ${ }^{i}$ FeTSPc: Iron tetrasulfophthalocyanine. ${ }^{j}$ NG: Nitrogen-doped graphene. ${ }^{k}$ NGA: Nitrogen-doped graphene aerosol. ${ }^{1}$ N-GP950: Nitrogen-doped electrochemical exfoliated graphene. ${ }^{\mathrm{m}}$ FeTAPc: Iron tetraaminophthalocyanine. ${ }^{\mathrm{n}}$ GQD: Graphene quantum dot.
}

Firstly, the development of new synthetic strategies for high performance hybrid catalysts is of great importance. For example, functionalized FePc derivatives with controlled chemical structures and tailored electronic structures can be considered because the performance of the composite ORR catalyst is closely related to the type and amount of adsorbed FePc molecules along with their electronic properties. In addition, the exploitation of alternative covalent approaches can be attempted to increase the ORR activity of the composite catalyst. So far, only simple amide and Fe-O-C bonds have been used for the preparation of covalently functionalized ORR composite catalysts. These linkages can belong to the $\mathrm{sp}^{3}$ hybridized bond category; thus, the efficient charge transporting phenomena between FePc and graphene can be significantly interrupted. Therefore, new preparation methods for the covalent 
anchoring of FePc molecules on graphene substrates through more favorable $\mathrm{sp}$ or $\mathrm{sp}^{2}$ linkages can enhance the ORR performance of the composite catalysts.

Secondly, the optimization of the size of graphene is worth considering, due to the crucial role of the conductive substrate in determining the catalytic performances of the composite catalyst. When smaller-sized graphene is applied, the number of active sites can be increased; however, the electrical conductivity of the conductive substrate can be deteriorated by a higher interfacial resistance originating from reduced grain size [54]. Although Koh et al. reported a promising ORR composite catalyst using graphene quantum dots as a conductive supporter [53], more in-depth studies on controlling the size of graphene substrates are expected to be highly beneficial for moving the technology forward.

Finally, the research on the detailed ORR reaction mechanism of FePc/graphene hybrid catalysts is highly demanding, but remain a challenge. Furthermore, the investigation on specific catalytic sites, dispersion condition, and the synergistic effects of hybrid catalysts is also insufficient. It is also noteworthy that these composite catalysts possess huge potentials in other promising electrochemical energy applications, such as hydrogen evolution reaction $[55,56]$ and photocatalytic oxidation reaction [57-59]. Although three plausible approaches for developing high-performance ORR composite catalysts have been proposed, there is still much room for further improvement of their performances. With continuous and innovative efforts, FePc/graphene composites can afford a promising pathway for energy conversion technologies like ORR based on scalable and non-precious approaches.

Author Contributions: Conceptualization, J.S.P. and D.W.C.; Writing-Original Draft Preparation, J.S.P. and D.W.C.; Writing-Review \& Editing, Supervision, D.W.C. All authors have read and agreed to the published version of the manuscript.

Funding: This work was supported by the Technology Innovation Program funded by the Ministry of Trade, Industry and Energy (MOTIE, 10047756) and National Research Foundation (NRF, 2018R1D1A1B07042822) of Republic of Korea.

Conflicts of Interest: The authors declare no conflict of interest.

\section{References}

1. Dixon, D.; Wippermann, K.; Mergel, J.; Schoekel, A.; Zils, S.; Roth, C. Degradation effects at the methanol inlet, outlet and center region of a stack MEA operated in DMFC. J. Power Sour. 2011, 196, 5538-5545. [CrossRef]

2. Deng, H.; Chen, J.; Jiao, K.; Huang, X. An analytical model for alkaline membrane direct methanol fuel cell. Int. J. Heat Mass Transf. 2014, 74, 376-390. [CrossRef]

3. Steele, B.C.; Heinzel, A. Materials for fuel-cell technologies. In Materials for Sustainable Energy: A Collection of Peer-Reviewed Research and Review Articles from Nature Publishing Group, 1st ed.; Dusastre, V., Ed.; World Scientific: Singapore, 2011; pp. 224-231.

4. Rivera-Lugo, Y.Y.; Pérez-Muñoz, K.I.; Trujillo-Navarrete, B.; Silva-Carrillo, C.; Reynoso-Soto, E.A.; Calva Yañez, J.C.; Lin, S.W.; Flores-Hernández, J.R.; Félix-Navarro, R.M. PtPd Hybrid Composite Catalysts as Cathodes for Proton Exchange Membrane Fuel Cells. Energies 2020, 13, 316. [CrossRef]

5. Yu, D.; Nagelli, E.; Du, F.; Dai, L. Metal-free carbon nanomaterials become more active than metal catalysts and last longer. J. Phys. Chem. Lett. 2010, 1, 2165-2173. [CrossRef]

6. Dai, L.; Xue, Y.; Qu, L.; Choi, H.-J.; Baek, J.-B. Metal-free catalysts for oxygen reduction reaction. Chem. Rev. 2015, 115, 4823-4892. [CrossRef]

7. Gong, K.; Du, F.; Xia, Z.; Durstock, M.; Dai, L. Nitrogen-doped carbon nanotube arrays with high electrocatalytic activity for oxygen reduction. Science 2009, 323, 760-764. [CrossRef] [PubMed]

8. Qu, L.; Liu, Y.; Baek, J.-B.; Dai, L. Nitrogen-doped graphene as efficient metal-free electrocatalyst for oxygen reduction in fuel cells. ACS Nano 2010, 4, 1321-1326. [CrossRef] [PubMed]

9. Pérez-Salcedo, K.; Shi, X.; Kannan, A.M.; Barbosa, R.; Quintana, P.; Escobar, B. N-doped porous carbon from Sargassum spp. As efficient metal-free electrocatalysts for $\mathrm{O}_{2}$ reduction in alkaline fuel cells. Energies 2019, $12,346$.

10. Li, M.; Zhang, L.; Xu, Q.; Niu, J.; Xia, Z. N-doped graphene as catalysts for oxygen reduction and oxygen evolution reactions: Theoretical considerations. J. Catal. 2014, 314, 66-72. [CrossRef] 
11. Gao, M.R.; Jiang, J.; Yu, S.H. Solution-based synthesis and design of late transition metal chalcogenide materials for oxygen reduction reaction (ORR). Small 2012, 8, 13-27. [CrossRef]

12. Sidik, R.A.; Anderson, A.B. Co9S8 as a catalyst for electroreduction of O2: Quantum chemistry predictions. J. Phys. Chem. B 2006, 110, 936-941. [CrossRef]

13. Roy, S.; Bandyopadhyay, A.; Das, M.; Ray, P.P.; Pati, S.K.; Maji, T.K. Redox-active and semi-conducting donor-acceptor conjugated microporous polymers as metal-free ORR catalysts. J. Mater. Chem. A 2018, 6, 5587-5591. [CrossRef]

14. Singh, S.K.; Crispin, X.; Zozoulenko, I.V. Oxygen reduction reaction in conducting polymer PEDOT: Density functional theory study. J. Phys. Chem. C 2017, 121, 12270-12277. [CrossRef]

15. Osgood, H.; Devaguptapu, S.V.; Xu, H.; Cho, J.; Wu, G. Transition metal (Fe, Co, Ni, and Mn) oxides for oxygen reduction and evolution bifunctional catalysts in alkaline media. Nano Today 2016, 11, 601-625. [CrossRef]

16. Liu, Y.; Ishihara, A.; Mitsushima, S.; Kamiya, N.; Ota, K.-I. Transition metal oxides as DMFC cathodes without platinum. J. Electrochem. Soc. 2007, 154, B664. [CrossRef]

17. Othman, R.; Dicks, A.L.; Zhu, Z. Non precious metal catalysts for the PEM fuel cell cathode. Int. J. Hydrog. Energy 2012, 37, 357-372. [CrossRef]

18. Bezerra, C.W.; Zhang, L.; Lee, K.; Liu, H.; Marques, A.L.; Marques, E.P.; Wang, H.; Zhang, J. A review of Fe-N/C and $\mathrm{Co}-\mathrm{N} / \mathrm{C}$ catalysts for the oxygen reduction reaction. Electrochim. Acta 2008, 53, 4937-4951. [CrossRef]

19. Zhang, Y.; Hu, Y.; Li, S.; Sun, J.; Hou, B. Manganese dioxide-coated carbon nanotubes as an improved cathodic catalyst for oxygen reduction in a microbial fuel cell. J. Power Sour. 2011, 196, 9284-9289. [CrossRef]

20. Nie, Y.; Li, L.; Wei, Z. Recent advancements in Pt and Pt-free catalysts for oxygen reduction reaction. Chem. Soc. Rev. 2015, 44, 2168-2201. [CrossRef]

21. Bezerra, C.W.; Zhang, L.; Liu, H.; Lee, K.; Marques, A.L.; Marques, E.P.; Wang, H.; Zhang, J. A review of heat-treatment effects on activity and stability of PEM fuel cell catalysts for oxygen reduction reaction. J. Power Sour. 2007, 173, 891-908. [CrossRef]

22. Bashyam, R.; Zelenay, P. A class of non-precious metal composite catalysts for fuel cells. Nature 2006, 443, 63-66. [CrossRef]

23. Long, N.V.; Thi, C.M.; Nogami, M.; Ohtaki, M. Novel Pt and Pd based core-shell catalysts with critical new issues of heat treatment, stability and durability for proton exchange membrane fuel cells and direct methanol fuel cells. In Heat Treatment-Conventional and Novel Applications, 1st ed.; Czwerwinski, F., Ed.; IntechOpen: London, UK, 2012; pp. 235-268.

24. Kiew, S.F.; Kiew, L.V.; Lee, H.B.; Imae, T.; Chung, L.Y. Assessing biocompatibility of graphene oxide-based nanocarriers: A review. J. Control. Release 2016, 226, 217-228. [CrossRef]

25. Liu, Y.; Yue, X.; Li, K.; Qiao, J.; Wilkinson, D.P.; Zhang, J. PEM fuel cell electrocatalysts based on transition metal macrocyclic compounds. Coord. Chem. Rev. 2016, 315, 153-177. [CrossRef]

26. Gu, W.; Hu, L.; Li, J.; Wang, E. Recent Advancements in Transition Metal-Nitrogen-Carbon Catalysts for Oxygen Reduction Reaction. Electroanalysis 2018, 30, 1217-1228. [CrossRef]

27. Alsudairi, A.; Li, J.; Ramaswamy, N.; Mukerjee, S.; Abraham, K.; Jia, Q. Resolving the iron phthalocyanine redox transitions for ORR catalysis in aqueous media. J. Phys. Chem. Lett. 2017, 8, 2881-2886. [CrossRef] [PubMed]

28. Ozoemena, K.I.; Pillay, J.; Nyokong, T. Preferential electrosorption of cobalt (II) tetra-aminophthalocyanine at single-wall carbon nanotubes immobilized on a basal plane pyrolytic graphite electrode. Electrochem. Commun. 2006, 8, 1391-1396. [CrossRef]

29. Ozoemena, K.I.; Nyokong, T. Surface electrochemistry of iron phthalocyanine axially ligated to 4-mercaptopyridine self-assembled monolayers at gold electrode: Applications to electrocatalytic oxidation and detection of thiocyanate. J. Electroanal. Chem. 2005, 579, 283-289. [CrossRef]

30. Agboola, B.O.; Ozoemena, K.I. Synergistic enhancement of supercapacitance upon integration of nickel (II) octa [(3, 5-biscarboxylate)-phenoxy] phthalocyanine with SWCNT-phenylamine. J. Power Sour. 2010, 195, 3841-3848. [CrossRef]

31. Ikeuchi, T.; Kudo, R.; Kitazawa, Y.; Mori, S.; Kimura, M. 3D Structural Optimization of Zinc Phthalocyanine-Based Sensitizers for Enhancement of Open-Circuit Voltage of Dye-Sensitized Solar Cells. Energies 2020, 13, 2288. [CrossRef]

32. Jasinski, R. A new fuel cell cathode catalyst. Nature 1964, 201, 1212-1213. [CrossRef]

33. Wiesener, K.; Ohms, D.; Neumann, V.; Franke, R. N4 macrocycles as electrocatalysts for the cathodic reduction of oxygen. Mater. Chem. Phys. 1989, 22, 457-475. [CrossRef] 
34. Chen, R.; Li, H.; Chu, D.; Wang, G. Unraveling oxygen reduction reaction mechanisms on carbon-supported Fe-phthalocyanine and Co-phthalocyanine catalysts in alkaline solutions. J. Mater. Chem. C 2009, 113, 20689-20697. [CrossRef]

35. Chen, Z.; Higgins, D.; Yu, A.; Zhang, L.; Zhang, J. A review on non-precious metal electrocatalysts for PEM fuel cells. Energy Environ. Sci. 2011, 4, 3167-3192. [CrossRef]

36. Şenocak, A.; Demirbaş, E.; Durmuş, M. Phthalocyanine-nanocarbon materials and their composites: Preparation, properties, and applications. In Nanocarbon and Its Composites, 1st ed.; Khan, A., Jawaid, M., Asiri, A.M., Eds.; Elsevier: Dubai, UAE, 2019; pp. 677-709.

37. Choi, H.-J.; Kumar, N.A.; Baek, J.-B. Graphene supported non-precious metal-macrocycle catalysts for oxygen reduction reaction in fuel cells. Nanoscale 2015, 7, 6991-6998. [CrossRef]

38. Son, H.; Yang, M.H.; Mutyala, A.K.; Chang, D.W.; Park, J.S. Superior electrocatalytic performance of polyisobutylene-substituted metallophthalocyanines supported on single-walled carbon nanotubes for an oxygen reduction reaction. Dyes Pigm. 2019, 162, 662-670. [CrossRef]

39. González-Gaitán, C.; Ruiz-Rosas, R.; Morallón, E.; Cazorla-Amorós, D. Relevance of the Interaction between the M-Phthalocyanines and Carbon Nanotubes in the Electroactivity toward ORR. Langmuir 2017, 33, 11945-11955. [CrossRef]

40. Liu, J.; Tang, J.; Gooding, J.J. Strategies for chemical modification of graphene and applications of chemically modified graphene. J. Mater. Chem. 2012, 22, 12435-12452. [CrossRef]

41. Jiang, Y.; Lu, Y.; Lv, X.; Han, D.; Zhang, Q.; Niu, L.; Chen, W. Enhanced catalytic performance of Pt-free iron phthalocyanine by graphene support for efficient oxygen reduction reaction. ACS Catal. 2013, 3, 1263-1271. [CrossRef]

42. Yu, D.; He, X. A novel iron (II) tetranitrophthalocyanine/graphene composite as the high-performance catalyst for the oxygen reduction reaction in an alkaline medium. Appl. Mater. Today 2016, 3, 1-10. [CrossRef]

43. Cui, L.; Lv, G.; He, X. Enhanced oxygen reduction performance by novel pyridine substituent groups of iron (II) phthalocyanine with graphene composite. J. Power Sour. 2015, 282, 9-18. [CrossRef]

44. Zhang, C.; Hao, R.; Yin, H.; Liu, F.; Hou, Y. Iron phthalocyanine and nitrogen-doped graphene composite as a novel non-precious catalyst for the oxygen reduction reaction. Nanoscale 2012, 4, 7326-7329. [CrossRef] [PubMed]

45. Liu, D.; Long, Y.-T. Superior catalytic activity of electrochemically reduced graphene oxide supported iron phthalocyanines toward oxygen reduction reaction. ACS Appl. Mater. Interfaces 2015, 7, 24063-24068. [CrossRef] [PubMed]

46. Taniguchi, T.; Tateishi, H.; Miyamoto, S.; Hatakeyama, K.; Ogata, C.; Funatsu, A.; Hayami, S.; Makinose, Y.; Matsushita, N.; Koinuma, M. A Self-Assembly Route to an Iron Phthalocyanine/Reduced Graphene Oxide Hybrid Electrocatalyst Affording an Ultrafast Oxygen Reduction Reaction. Part. Part. Syst. Char. 2013, 30, 1063-1070. [CrossRef]

47. Wang, R.-X.; Yang, X.-D.; Wan, L.-Y.; Lu, B.-A.; Shen, L.-F.; Li, Y.-Y.; Sun, S.-G.; Zhou, Z.-Y. Graphene-covered FePc as a model of the encapsulated type of catalyst for the oxygen reduction reaction. Electrochem. Commun. 2020, 112, 106670. [CrossRef]

48. Gao, X.; Wang, J.; Ma, Z.; Ye, J. Iron tetrasulfophthalocyanine functionalized graphene nanosheets for oxygen reduction reaction in alkaline media. Electrochim. Acta 2014, 130, 543-550. [CrossRef]

49. Yin, H.; Zhang, C.; Liu, F.; Hou, Y. Hybrid of iron nitride and nitrogen-doped graphene aerogel as synergistic catalyst for oxygen reduction reaction. Adv. Funct. Mater. 2014, 24, 2930-2937. [CrossRef]

50. Komba, N.; Zhang, G.; Wei, Q.; Yang, X.; Prakash, J.; Chenitz, R.; Rosei, F.; Sun, S. Iron (II) phthalocyanine/N-doped graphene: A highly efficient non-precious metal catalyst for oxygen reduction. Int. J. Hydrog. Energy 2019, 44, 18103-18114. [CrossRef]

51. Liu, Y.; Wu, Y.-Y.; Lv, G.-J.; Pu, T.; He, X.-Q.; Cui, L.-L. Iron (II) phthalocyanine covalently functionalized graphene as a highly efficient non-precious-metal catalyst for the oxygen reduction reaction in alkaline media. Electrochim. Acta 2013, 112, 269-278. [CrossRef]

52. Guo, J.; Yan, X.; Liu, Q.; Li, Q.; Xu, X.; Kang, L.; Cao, Z.; Chai, G.; Chen, J.; Wang, Y. The synthesis and synergistic catalysis of iron phthalocyanine and its graphene-based axial complex for enhanced oxygen reduction. Nano Energy 2018, 46, 347-355. [CrossRef]

53. Koh, K.H.; Noh, S.H.; Kim, T.-H.; Lee, W.J.; Yi, S.-C.; Han, T.H. A graphene quantum dot/phthalocyanine conjugate: A synergistic catalyst for the oxygen reduction reaction. RSC Adv. 2017, 7, 26113-26119. [CrossRef] 
54. Chang, D.W.; Choi, H.-J.; Jeon, I.-Y.; Seo, J.-M.; Dai, L.; Baek, J.-B. Solvent-free mechanochemical reduction of graphene oxide. Carbon 2014, 77, 501-507. [CrossRef]

55. Yang, L.; Mukhopadhyay, A.; Jiao, Y.; Hamel, J.; Benamara, M.; Xing, Y.; Zhu, H. Aligned and stable metallic MoS 2 on plasma-treated mass transfer channels for the hydrogen evolution reaction. J. Mater. Chem. A 2017, 5, 25359-25367. [CrossRef]

56. Akyüz, D.; Dinçer, H.; Özkaya, A.R.; Koca, A. Electrocatalytic hydrogen evolution reaction with metallophthalocyanines modified with click electrochemistry. Int. J. Hydrog. Energy 2015, 40, 12973-12984. [CrossRef]

57. Li, X.; Le, Z.; Chen, X.; Li, Z.; Wang, W.; Liu, X.; Wu, A.; Xu, P.; Zhang, D. Graphene oxide enhanced amine-functionalized titanium metal organic framework for visible-light-driven photocatalytic oxidation of gaseous pollutants. Appl. Catal. B Environ. 2018, 236, 501-508. [CrossRef]

58. Kumar, P.; Singh, G.; Tripathi, D.; Jain, S.L. Visible light driven photocatalytic oxidation of thiols to disulfides using iron phthalocyanine immobilized on graphene oxide as a catalyst under alkali free conditions. RSC Adv. 2014, 4, 50331-50337. [CrossRef]

59. Zhang, G.; Liu, B.; Zhou, H.; Yang, Y.; Chen, W.; Zhao, J. Graphene wrapped phthalocyanine: Enhanced oxidative desulfurization for dibenzothiophene in fuel. Appl. Organomet. Chem. 2018, 32, e4477. [CrossRef]

(C) 2020 by the authors. Licensee MDPI, Basel, Switzerland. This article is an open access article distributed under the terms and conditions of the Creative Commons Attribution (CC BY) license (http://creativecommons.org/licenses/by/4.0/). 